\title{
As Palavras ou os Preconceitos da Infância*
}

\author{
Gérard Lebrun
}

Que interesse, perguntava mais ou menos Rousseau, teria a autobiografia, se consistisse apenas em descrever um caráter ou narrar acontecimentos? E acrescentava: ao escrever minhas Confissões, não pretendo contar minha história, mas sim dar a cada um a ocasião de conhecer de agora em diante, ao mesmo tempo que a si mesmo, um Outro que entre os outros aceita tornar-se o quadro de referência que todos poderão consultar, se tentarem conhecer a outrem como a si mesmo: tal é o projeto. Além disso, Rousseau assegura que escreve menos "a história dos acontecimentos de sua vida em si mesmos que a do estado de sua alma à medida que eles se deram" (Rousseau 1, p. 1150). Com isso, a autobiografia deixa de ser um "romance engenhoso" ou um divertimento de diletante (é assim que Rousseau julga Montaigne); adquire um sentido novo. Não é mais a mim que eu peço que admirem ou lastimem, nem mesmo é pela "humana condição" que testemunho, mas pela universalidade ao nível da qual cada um pode reconhecer cada um e reconhecer-se nele: "Ser eterno, reúne em torno de mim a inumerável multidão de meus semelhantes... Que cada um deles descubra por sua vez seu coração com a mesma sinceridade..." (Rousseau 1, p. 5) .

Reportemo-nos agora à última frase de As Palavras de Sartre. A ênfase desapareceu, mas a intenção universalista permanece: 
"O que resta? Todo um homem, feito de todos os homens, que os vale todos e a quem vale não importa quem." (Sartre 3, p. 213; 4, p. 158)

Mais ainda: pode-se ler as Confissões como um romance. As Palavras, não. Nada é menos anedótico que esse curto relato, em que as recordações de infância e de família - no sentido habitual - são reduzidas ao mínimo. Se Rousseau dava muita importância ao que chamava "as causas ocasionais", Sartre é menos generoso para com "as forças externas":

"Eis o meu começo: eu fugia, forças externas modelaram minha fuga e me criaram." (Sartre 3, p. 207; 4, p. 154)

Trata-se então de um inventário psicológico? Sobre isso, ainda, Sartre presta-se menos ao equívoco do que Rousseau. Sem dúvida, o autor resume o que foram os sonhos e os pensamentos secretos de sua primeira juventude, mas nunca os apresenta como esboços de um caráter, etapas de uma "psique" em elaboração. Nenhum relato em primeira pessoa pode ser mais pudico nem mais anônimo: trata-se de uma criança morta que, ela própria, nos é dito, nunca se havia considerado demasiadamente como viva, "um menino muito novo e já velho, já morto" (Sartre 3, 203; 4, 151). Quem fala, de resto? Sartre em 1963. Unicamente ele. E ele nunca procura ser o porta-voz do menino que foi. Muito pelo contrário: a essa criança, empresta sua voz, seu estilo. Quem fala? É a criança Sartre habitada pelo filósofo que se tornou, devorada pelo olhar de um adulto que, durante muito tempo, não se preocupara com ela.

"Meus primeiros anos, sobretudo, eu os risquei: quando comecei este livro, precisei de muito tempo para decifrá-los sob as rasuras.

Alguns amigos se admiraram, quando eu tinha trinta anos: Dir-se-ia que você não teve pais. Nem infância." (Sartre 3, p. 199; 4, p. 148)
Para compreender seu porte desenvolto, sua despreocupação para com todos os usos da narração íntima, é bom talvez voltar-se para outro clássico.

"Pelo fato de termos sido crianças antes de sermos homens (...) é quase impossível que nossos julgamentos sejam tão puros ou tão sólidos como seriam se tivéssemos tido o uso inteiro de nossa razão desde o ponto de nosso nascimento, e não tivéssemos sido conduzidos senão por ela." (Descartes)

Sartre é mais violento.

"O leitor compreendeu que detesto minha infância e tudo que dela sobrevive" (Sartre 3, p. 137; 4, p. 104) - "À falta de uma criança, tome-se um canicho (...) os cães sabem amar; são mais ternos do que os homens, mais fiéis (...) quando se ama demais às crianças e aos animais, a gente os ama contra os homens." (Sartre 3, p. 21; 4, p. 21)

É que para Sartre, para Descartes, a infância é uma fileira de amadilhas, é a soma dos preconceitos dos quais mais tarde nunca chegaremos a nos libertar completamente. "A infância é conformista" (Sartre 3, p. 188; 4, p. 141) . É a idade em que somos abandonados sem defesa às mais estúpidas mistificações e ao mesmo tempo a origem traumatizante do que acreditamos mais tarde ser nossa singularidade infinita. Dupla razão para que os amantes de idéias claras suspeitem dela, dupla razão para que as "belas almas" se refugiem nela ou pelo menos a apreciem. Outrora, em seu Baudelaire, Sartre descreveu cruelmente esse momento em que a criança faz a experiência deslumbrada de sua subjetividade psicológica, de sua diferença íntima, sente que não é qualquer pessoa - começa a tornar-se "o homem que nunca se esquece" : macaquinho burquês já travestido em Narciso. Sartre tem razão. Por que François Mauriac, se não fosse católico, burguês e proprietário, iria lembrar-se tão vivamente de sua juventude no colégio dos Bons Pères e das vítimas de Natal que admirava na Bordéus de 
sua infância? Foi nesses instantes que seu Eu lhe foi revelado, assim como essa subjetividade que Sartre gosta de chamar exquise. Tenho notado frequientemente que os operários têm menos respeito que nós por sua infância, menos fetichismo de seus primeiros brinquedos (quando os tiveram). Tornam-se acultos mais cedo que nós; passaram suas férias em colônia; chamam seus pais de "seus velhos". Evitaram esses paraísos envenenados que nos convencem de que temos alma. É criminoso, repete-se facilmente, tirar as ilusões da criança: dêem-lhe tempo para que as perca... Desses lugarescomuns imbecilizantes os cartesianos nos preservam: segundo eles, nunca é cedo demais para desembaraçar-se dos "falsos preconceitos da infância". Tanto através do Discurso quanto através de As Palavras, sente-se correr a mesma impaciência: não a nostalgia do tempo passado, mas o agastamento com a idéia do tempo perdido - a queixa de ter podido ser joguete de tolos porque eles eram adultos.

"Minha verdade, meu caráter e meu nome estavam nas mãos dos adultos: aprendera a ver-me com os olhos deles; eu era uma criança, esse monstro que eles fabricam com suas queixas." (Sartre 3, p. 66; 4, p. 53)

A partir disso, contar sua infância não pode ser outra coisa senão forçála às confissões, denunciar bem alto o destino que ela quase nos traçou expulsar de nós, também, os últimos germes dessa longa doença. Não há nenhuma frase, no relato de Sartre, que não suponha esse brutal distanciamento. É ele que justifica a ferocidade dos retratos de família, a ironia que o autor emprega ao evocar o pai que não chegou a conhecer - toda a cínica alegria que dá ao livro seu ritmo. É também ele que faz compreender o curto-circuito contínuo entre o narrador qüinquagenário e o garoto cuja história ele narra: o acontecimento passado só tem interesse quando refletido em minha liberdade atual, criticado por minha consciência de si; - e esse comentário perpétuo já é "cal viva em que se dissolve a maravi lhosa infância". Fale-se de maldade, se se quiser, mas sobretudo não se fale de anacronismo. É verdade que Sartre, para melhor destruir esse pirralho que detesta, fá-lo pronunciar sua autocrítica. Mas sua filosofia lhe dá esse direito. Eu me comunico inteiramente com aquele que fui: dele, nada é misterioso ou sagrado: ele não é um Outro, como o jovem em que o amnésico - em O Viajante sem Bagagens de Anouilh - hesita em reconhecer-se. Não há anacronismo - e mesmo maldade a não ser na perspectiva, contestada a partir de $O$ Ser e o Nada - da "duração psicológica": se a espessura do tempo me separasse de meu Eu antigo, seria absurdo sem dúvida pretender falar em seu nome, julgá-lo no atual. Mas esse "tempo" é um mito bergsoniano de que Sartre faz tão pouco caso quanto Bergson do "tempo dos relógios", da mesma forma que esse "Eu" tão querido é invenção dos insensatos e consolação dos salauds. Não há atrás de mim nenhum segredo naufragado e nada me separa de nenhum instante de minha vida, de nenhum rosto que tive. Não haveria anacronismo a não ser que o autor intenpretasse sua vida de antanho à luz de suas opiniões de hoje e substituísse indevidamente estas no seio daquelas. Mas esse erro de método só seria possível se eu pudesse repartir minha vida em um "antes" e um "depois". Ora, para Sartre, esses cortes em uma vida são tão arbitrários quanto ao olhar do Deus cartesiano uma distinção entre os instantes da criação continuada.

"A duração psicológica que conhecemos e de que fazemos uso cotidianamente, enquanto sucessão de formas temporais organizadas, é o oposto da historicidade... De fato, se se apreende o para-si em sua historicidade, a duração psíquica se desvanece, os estados, as qualidades e os atos desaparecem para dar lugar ao ser-para-si enquanto tal, que é somente como a individualidade única cujo processo de historialização é indivisível. É ele que flui, que se chama do fundo do porvir, que historializa sua ipseidade..." (Sartre 2, p. 205-6)

É por isso que a reflexão autêntica nunca encontra o refletido em face de si como um objeto opaco (outra tese cartesiana) - mesmo quando esse objeto é o meu passado. É por isso que nada deste pode escapar-me e nada nele desmentir o que posso dizer a seu respeito: ele e eu - desde que nos situemos fora da temporalidade degradada dos psicólogos - somos inundados pela mesma luz, o mesmo instante fulgurante nos reúne. Minha infân- 
cia não estava perdida para sempre, só conservava uma auréola mítica enquanto eu caía nas armadilhas da psicologia - enquanto eu me acreditava homo psychologicus, povoado de representações e imagens insubstituíveis que deslizariam para dentro de um passado "irreversível", materializado depois como esteira de minha vida. Desde que eu seja o Deus de Descartes, tudo muda (e veremos como, nesse relato fantástico, a criança que nos é descrita se transforma nele, à sua maneira) : estou ao mesmo tempo (se se pode dizer assim) em cada um dos meus momentos (se se pode dizer assim) - inteiramente reunido no mesmo ponto do tempo originário que nada tem a ver com o tempo da sucessão, da puberdade e do envelhecimento... - Parece que estou extrapolando; mas tento explicitar os pressupostos que tornam esse livre estranho por tornarem insólita a "temporalidade" em que ele se desenvolve. Nunca ninguém tinha falado assim de sua infância, com tal desdém e tal despreocupação com as ilusões retrospectivas. Nunca - a não ser, creio, o Deus de Descartes, se pudesse ter tido infância.

Tanto outrora como agora, meu projeto é portanto o mesmo - variável, sem dúvida, na medida das circunstâncias, mas idêntico graças a esse jorrar contínuo que assegura ao mesmo tempo sua singularidade e sua unidade. Seria pois desonesto acusar Sartre de ter marcado as cartas ao trocar seu "Eu" de hoje pelo seu Eu de outrora. Através do relato, procuremos apenas ver esboçarem-se as primeiras figuras de uma "escolha livre". De uma "escolha livre" entre outras - tais como as de Baudelaire ou de Jean Genet que Sartre já tomou como exemplos nas biografias existenciais que deles traçou. No passado de Sartre, contado por ele, não há mais acaso que na vida desses poetas ou de qualquer homem. Nem mais necessidade mecânica, naturalmente. Há apenas, desde o começo, um projeto fundamental se não totalmente conhecido, ao menos totalmente consciente - que unificava os sonhos e as loucuras de uma criança. Por ridículo que tenha sido o garoto pretensioso que Sartre nos descreve, vale portanto a pena compreender, através de seu exemplo, como uma liberdade nova, mesmo afundandose na irrisão de uma família conformista, pôde abrir seu caminho. Como essa pré-história de um para-si foi de qualquer modo vivida inteiramente (admitamos os pressupostos de Sartre) no modo do para-si. Deixemos de lado a juventude de Sartre como homem privado ou como homem célebre: é ele mesmo que nos convida a fazê-lo - e examinemos mais de perto as etapas dessa Erziehung que é, mais que o memorial de um filósofo, a contraprova de uma filosofia.

Na família Schweitzer - a de seu avô - em que vive o menino Sartre, todo mundo representa. Ninguém sente a não ser aquilo que representa. 0 avô, patriarca farisaico de barba caudalosa, tira partido de cada efusão para representar A Arte de Ser Avô, de Victor Hugo.

"Tinha a sorte e a desgraça de ser fotogênico; suas fotos enchiam a casa; como não se praticava então o instantâneo, adquirira o gosto pelas poses e pelos quadros vivos; tudo lhe servia de pretexto para suspender os gestos, para paralisar-se numa bela atitude, para petrificar-se, adorava aqueles curtos instantes de eternidade em que se tomava sua própria estátua" (Sartre 3, p. 15-6; 4, p. 18)

Deixemos isso de lado. Sartre conheceu sua família e seu avô melhor que nós. Mas não nos esqueçamos de que o mesmo homem que fustiga dessa maneira a família Schweitzer pôde também descrever uma manifestação comunista em Paris, em 1952, como uma representação que o proletariado parisiense, na rua, se dava de si mesmo... Admiro muito Sartre, mas desconfio dele quando seu talento e sua verve o arrastam - e não irei julgar seu avô de acordo com essa acusação. Aliás, ela me parece preparar muito bem o que segue. Uma vez que toda a família está em cena, o menino, por sua vez, torna-se um impostor, atento a adular o avô, a executar os gestos que sabe serem esperados dele. Pois ele o sabe: o Cogito cartesiano não perde seus direitos na família Schweitzer, assim como não os perde entre os psicopatas em $O$ Imaginário.

"Uma transparente certeza estragava tudo: eu era um impostor. Como representar a comédia sem a gente saber que a representa?" (Sartre 3, p. 67; 4, p. 53) 
Eis pois o menino desdobrado, representando mesmo na solidão sua personagem de "pequena maravilha". Em suma, sempre à distância dela e entretanto com a maior seriedade do mundo. Eis além disso Sartre em um terreno a que é muito afeiçoado: o "comediante" é um de seus paradigmas preferidos. Ao mesmo tempo que sabe que não é sua personagem, o comediante a é inteiramente: não é outra coisa que suas palavras e seus gestos. O comediante está à distância dela; mas a palavra "distância", neste caso, é uma metáfora enganadora. Enquanto uma distância separa positivamente uma coisa de outra, nada, aqui, me separa de mimmesmo. Assim, na consciência de si, a simples presença do genitivo parece indicar que sou dois; mas que se analise essa qualidade: ela se reabsorve em identidade absoluta, coincidência perfeita consigo. É por isso que, sendo todos comediantes, somos todos cabotinos, todos estamos de má-fé. Essa distância, de que antes eu me orgulhava, não é nada. De maneira que, ao descobrir meu cabotinismo integral, desvendo meu Nada: não havia ninguém sob a máscara.

"Tentara refugiar-me em minha verdade solitária; mas eu não dispunha de verdade alguma" (Sartre 3, p. 89; 4, p. 69) . "Eu era nada." (Sartre 3, p. 73; 4, p. 57)

Revelação que, ao mesmo tempo, me introduz a um Cogito mais puro e mais rigoroso que o de Descartes - aquele mesmo em que, segundo Sartre, Descartes não conseguiu manter-se. É certo que Descartes escrevia:

"Eu não sou essa reunião de membros que se chama o corpo humano; não sou um ar tênue penetrante, disseminado por todos esses membros; não sou um vento, um sopro, um vapor nem algo que posso fingir e imaginar..."

Mas através de todas essas negaçães, eu continuo a ser todavia, segundo Descartes, uma coisa que pensa. o Cogito sartriano não chega até aí:
"Eu não era consistente nem permanente; eu não era o continuador futuro da obra paterna, eu não era necessário à produção do aço: em suma, eu não tinha alma." (Sartre 3, p. 71; 4, p. 56)

Mas como encarar por muito tempo uma verdade tão sombria? A comédia familiar acaba de acuar o menino a uma tomada de consciência da qual ele deve fugir sob pena de loucura; - e o livro, a partir de então, tomase o recenseamento de algumas figuras da má-fé infantil.

"Nasci para satisfazer a grande necessidade que eu tinha de mim mesmo; conhecera até então apenas as vaidades de um cão de luxo; acuado no orgulho, tornei-me o Orgulhoso. . . Neste ponto extremo da humildade, não podia mais me salvar a não ser invertendo a situação."

(Sartre 3, p. 90; 4, p. 69-70)

1̄a figura. O menino, espontaneamente, se faz outro. À comédia oficial que o obrigam a representar, ele acrescenta outra, secreta - na qual possa acreditar. Utilizando suas leituras, imagina-se herói, explorador, voando em socorro dos fracos, transpassando os maus. Mas a alienação é um empreendimento de fôlego. Não é tão fácil tornar-se D. Quixote. No cinema a que a mãe o levava, o menino pode perfeitamente identificar-se com as personagens - mas apenas enquanto dura a projeção.

"Eu sentira sua vitória em meus ossos, todavia era a delas e não a minha: na rua, eu voltava a ser extranumerário." (Sartre 3, p. 102; 4, p. 78)

\section{É preciso portanto urdir um novo ardil.}

2a figura. O menino começa a escrever relatos, a princípio simples plágios ou reminiscências que, lentamente, tornam-se doras de imaginação. Como a adulação familiar favorece isso, ele se deixa levar pelo jogo. Ele, 
que se acreditava "de sobra", ei-lo encarregado de um mandato: escreverá... Tudo iria bem, se o avô, agastado por achar que viravam a cabeça do garoto, não o convidasse a "encarar as coisas com lucidez". Habilmente, fá-lo duvidar desse gênio assegurado depressa demais. Sem dúvida, ele é dotado; mas seria essa uma razão para que vá "viver de sua pena"? Entrará na Escola Normal, tornar-se-á professor, escreverá artigos em um jornal de província... O menino, convencido, resigna-se a essa missão menos gloriosa. Mas a miragem dissipou-se.

"No dom que Karl me reconhecia com desdém, julgando inábil negálo totalmente, eu não via, no fundo, senão um acaso incapaz de legitimar este outro acaso, eu mesmo... Meu orgulho e meu abandono eram tais, na época, que eu almejava ser morto ou requerido pela terra inteira." (Sartre 3, p. 37-8; 4, p. 45)

Aos nove anos, eis a $3^{\text {a }}$ figura.

"No momento de me resignar, fui acometido de violento sobressalto ... lancei-me a uma operação simples e demente que desviou o curso de minha vida: escorreguei ao escritor os poderes sagrados do herói." (Sartre 3, p. 139; 4, p. 106)

Os escritores não são solitários: a humanidade necessita tanto deles quanto dos cavaleiros errantes ou dos vingadores de injustiça. Ou melhor: o escritor, testemunhando a favor do homem, o salva.

"Tornei-me cátaro, confundi a literatura com a prece, converti-a em sacrifício humano... Tomei o alvitre de escrever para Deus com o fito de salvar meus vizinhos. Eu queria devedores de obrigações e não leitores." (Sartre 3, p. 149-50; 4, 113-14)
Desta vez, a tentativa vai ter êxito. Menino abstrato e estudioso, 0 jovem Sartre assume sua abstração e, definitivamente, a sublima. Já preferia os livros às coisas; por muito tempo vai preferir as obras de arte aos homens. Em linguagem sartriana, ei-lo "esteta", se estética significa transformação do mundo em aparência de mundo. Essa suprema impostura decide sua vida; Sartre encontra o prolongamento dela em suas primeiras obras: A Náusea, O Ser e o Nada.

"Consegui aos trinta anos dar esse belo golpe: o de escrever em $A$ Náusea - muito sinceramente, podem crer - a existência injustificada, salobra, de meus congêneres e colocar a minha fora de causa... Mais tarde expus jovialmente que o homem é impossível; eu próprio impossível, diferia dos outros apenas pelo simples mandato de manifestar essa impossibilidade que, no mesmo lance, se transfigurava... Falsificado até os ossos e mistificado, escrevia alegremente sobre nossa infeliz condição." (Sartre 3, p. 210; 4, p. 156)

Egoísta, inconsciente, desprezando os homens e dando o nome de generosidade a seu orgulho: eis o que sua infância fez dele. Uma família burguesa constrangeu-o à alienação; a cultura burguesa acaba de fornecer-lhe o álibi... Pode-se imaginar autocrítica mais rude? Um homem confessa que sua vida foi forjada à força de imposturas. Sua vocação, sua indiferença para consigo, o sacrifício alegre que faz de sua vida pessoal os livros que escreverá, ele, o anônimo - tudo nasceu dessa "operação fraudulenta".

"Desde os nove anos de idade, uma operação privou-me dos meios de sentir um certo patético que dizem próprio de nossa condição." (Sartre 3, p. 162; 4, p. 123) - "Escolhi como porvir um passado de grande morto e tentei viver ao revés. Entre nove e dez anos, torneime completamente póstumo." (Sartre 3, p. 165; 4, p. 125) 
O mandato que ele se havia outrora confiado tornou-se seu caráter: ele o reconhece. O retrato final que traça de si próprio é um balanço dos desvios de seu nono ano. "Todos os traços da criança remanescem no qüinquagenário". E, embora não creia mais que os escritores estejam destinados a salvar o mundo, ele escreve sempre. "Que outra coisa fazer?" Daí a confissão final.

"Esse velho edifício ruinoso, minha impostura, é também meu caráter: a gente se desfaz de uma neurose, mas não se cura de si próprio." (Sartre 3, p. 211; 4, p. 157)

Mas enfim, dir-se-á, esse sentido irrisório que o autor confere a seu passado, e em seguida a sua personalidade inteira, é ainda ele que o dá. Ao condenar-se totalmente, Sartre se salva. Quer queira quer não, ele joga o "perde-ganha" de toda confissão: pelo fato de reconhecer meu erro, já estou além dele; ao proclamar minha singularidade, faço-me universal e restauro a meu favor a dualidade da consciência de si... Diante desta acusação de farisaísmo sutil, Sartre daria de ambros. Não, replicaria: não sou nada mais que aquilo que descrevo, colo-me a essa personagem e seria totalmente incapaz de julgar-me do alto de algum tribunal íntimo, por esta boa razão: esse Eu - que no caso os senhores me supõem - não existe. Essa lucidez total é um predicado sem sujeito. O autor, no momento em que escreve e se condena, não pode ser essa personagem ardilosa que pretenderia tirar partido de sua confissão: ele não é mais que seu ato, não está em lugar nenhum, não é nada. Uma subjetividade pode trapacear; o Nada, não.

Seja. Não imputemos a algum Eu secreto essa lucidez frenética: ela é o outro nome da liberdade. Mas eis aqui, então, outra dificuldade: essa liberdade, por sua vez, é pemanente. E é por isso que foi tanto o apanágio do menino quanto é do adulto, sub-repticiamente escondida no seio dos piores delírios... Há uma coisa notável nesse relato de uma mistificação que se pretende vitoriosa: a consciência de si sempre habita a consciência mentirosa e vem envenenar a felicidade. O que Hegel chama de "Para-nós" não está situado no fim da história: está presente em cada etapa, real e atual- mente. Merleau-Ponty escreveu que Sartre não podia admitir, como os marxistas, que houvesse consciências totalmente mistificadas. "Para Sartre, não pode haver tolos; apenas canalhas". Sabemos agora que para Sartre também não há crianças mistificadas: há apenas impostorezinhos -e a inteligência dessa criança só era igualada por sua malignidade... É pois impossível iludir-se completamente? Sim: impossível. Sem dúvida, posso, definitivamente, tomar-me por um gênio futuro e, definitivamente, consolar-me assim de meu Nada entrevisto; sem dúvida, há um mau imaginário cujas figuras surgem em mim sem convocação: o do sonho, da alucinação; sem dúvida, em qualquer idade, a demência é possível e a singularidade egoísta pode triunfar sobre a consciência de si (é assim que Hegel, na Enciclopédia, descreve - "gênio mau" da loucura). Mas há uma coisa, segundo Sartre, que esse "gênio mau" não pode fazer: que eu não reconheça meus sonhos como sonhos - que eu me minta sem me reencontrar mentindo-me, pelo menos no modo da consciência irrefletida. E não é preciso mais nada para que, restabelecido o imaginário em sua falsidade intrínseca, eu o seja, quanto a mim, por oposição, em minha verdade. Assim o menino Sartre não chegava a cegar-se: bem sabia que seu "mandato" de escritor não provinha do céu.

"Não podia esquecer que era eu próprio quem mo atribuía. Surgido de um mundo antediluviano, no instante em que escapava à Natureza para tornar-me enfim eu, esse Outro que eu pretendia ser aos olhos dos outros, eu fitava de frente o meu Destino e eu o reconhecia: não era senão minha liberdade, erguida por mim, diante de mim, como um poder estranho. Em suma, eu não conseguia me embruIhar inteiramente." (Sartre 3, p. 142; 4, p. 108)

E é por isso que uma leitura otimista pode duplicar a leitura pessimista que fazíamos há pouco. Esse imaginário que Sartre apresenta como alienante, é o reverso de uma verdade, por mais deplorável que ele a julgue hoje: ao escrever seus sonhos, o menino se torna realmente imaginário. Em seu Genet, Sartre já descreveu esse momento em que, no momento de "engolfar-se no imaginário", Genet "se apercebe de que sonha", e, desde 
então, decide assumir seu sonho, ser sonhador. "Por essa decisão, escapa ao sonho, uma vez que transforma um sonho de vontade em vontade de sonho." (Sartre 5, p. 327) Ora, Sartre imputa a si mesmo cedo demais essa tomada de consciência que imputa tarde demais a Genet.

"Não era preciso mais. Eu escapava à comédia: não trabalhava ainda, porém não brincava mais, o mentiroso encontrava sua verdade na elaboração de suas mentiras. Eu nasci da escrita... Eu, isso significava: eu que escrevo..." (Sartre 3, p. 127; 4, p. 97)

Isso foi sua perdição como homem, assegura-nos hoje - o início de uma doença de que acaba de restabelecer-se. Sem dúvida. Mas foi também o nascimento de sua liberdade ou antes o encontro com ela. E é bem o caso de dizer mais uma vez que a história avança pelo seu lado mau. De resto, esse é um enredo que aparece frequientemente em Sartre: é possível conquistar-se contra o imaginário, por ruptura com os mitos. Mas é possível também conquistar-se através do imaginário: tal obstáculo é também uma mediação e essa passagem pelo reino das sombras não é inteiramente negativa. É o imaginário, mesmo desregrado, que, de preferência, me anuncia minha liberdade; é a má-fé que, em O Ser e o Nada, preludia a análise do para-si. "Sei que sonho ou que minto, logo sou". Sei que posso nadificar o mundo e projetar-me no irreal, para além dele: sou pois outra coisa que ele e meu verdadeiro Nada surge através desses falsos prestígios. Assim o Jean Genet é a fenomenologia otimista de uma consciência que passa, sem descontinuidade, da contemplação narcisista à liberdade objetiva pela mediação do narcisismo refletido em poesia. Em Orfeu Negro, o esquema é o mesmo: ao descobrir seu exílio e sua inconsistência no seio de uma cultura que não é a sua, enfim sua irrealidade, o Negro, espontaneamente, se faz poeta: celebra seu Nada sob o nome de "negritude". Sem dúvida, essa etapa é ainda mistificante. Mas é sobretudo necessária: "escolhendo ver aquilo que é, ele se desdobrou, não coincide mais consigo mesmo" (Orfeu Negro, p. 240) , e a poesia é o embrião da tomada de consciência revolucionária.
Onde um marxista veria simplesmente um mecanismo de compensação, Sartre percebe muito mais: a primeira manifestação da liberdade.

"Por ser uma subjetividade que se inscreve no dbjetivo, a Negritude deve tomar corpo em um poema, isto é, em uma subjetividade-objeto... não pode fazer-se ouvir e oferecer-se a não ser por meio da obra de arte que é apelo à generosidade do espectador e generosidade absoluta." (Orfeu Negro, p. 284)

"Triunfo do narcisismo e suicídio de Narciso", dizia ainda Sartre da descoberta da Negritude. Quando descreve hoje aquilo que, na infância, foi o equivalente disso, ele parece mais severo: apresenta essa liberação esboçada como uma impostura, essa "realização do imaginário" como um estratagema a mais. "Eu confundi deliberadamente a arte de escrever e a generosidade." (Sartre 3, p. 141; 4, p. 107) Dir-se-ia que Sartre gostaria de ser o historiógrafo marxista - e o mais sectário que se possa imaginar - de sua juventude burguesa. Mas não chega a isso. É em nome de sua liberdade de hoje que ele zomba de sua liberdade estragada de outrora; Sartre evoluiu, certamente, mas através das mesmas estruturas que, quanto a elas, continuam válidas. Essa ira fria contra si próprio atesta ainda e mais que nunca "a morte de Narciso"; é portanto a herança do menino que descobriu um dia que não tinha alma e que, bem ou mal, tentou então preencher esse vazio. Tentativa ridícula e desonesta, exclama hoje Sartre; mas seria ele tão inexorável para consigo mesmo se essa infância que ele estraçalha não lhe tivesse fornecido as armas? Juiz impiedoso, ele arrasa sua vida inteira. Mas foi há bastante tempo - há sete anos, diz-nos - que tomou consciência desse poder negador que hoje exerce. Bem antes de ter lido Descartes tinha transferido para o homem a onipotência do Deus cartesiano, cuja sentença, que prenuncia agora contra si mesmo, não passa nunca de um decreto a mais.

"Alguém poderá pensar que eu era muito presunçoso. Não: eu era órfão de pai. Filho de ninguém, fui minha própria causa, cúmulo de orgulho e cúmulo de miséria..." (Sartre 3, p. 91; 4, p. 70) 
Mais feliz do que Baudelaire, como o descreveu, mais precoce do que Genet, foi pois muito cedo que matou Narciso, muito cedo que se tornou o que chamará mais tarde "um campo transcendental sem sujeito". Mais uma vez, o triunfo do narcisismo foi o reverso de uma vitória secreta, mais durável que o próprio narcisismo. Nas festas egocêntricas que o menino Sartre dava a si mesmo, ele se libertava ao menos de seu Ego empírico; fazendo-se imaginário e pelo próprio fato de tomar-se imaginário, não perdia de vista essa mesma liberdade que agora the permite voltar-se contra si próprio. Continuava a ser mestre desse jogo a que se entregava. Sartre não mudou desde que, em O Imaginário, sustentava que o sonho noturno é um jogo e que há, afinal de contas, jogos aos quais "a gente se entrega totalmente". o que significa que, por mais que a gente se irrealize, não seria possível irrealizar-se inteiramente - que a consciência mistificada não deixa de ser uma variedade da consciência fundamental, aquela que é tudo porque não é nada, que é onipresente porque não está em lugar nenhum. É dessa forma que, aos oito anos, Sartre vivia sua vocação do grande escritor futuro que sonhava ser. Por mais que ache uma farsa essa ambição, ele não pode impedi-la de confundir-se com a própria linguagem de que se serve para criticá-la.

"Lêem-me, salto aos olhos, falam-me, estou em todas as bocas, língua universal e singular (...) para quem me sabe amar, sou sua inquietude mais íntima, mas, se ele quer me tocar, apago-me e desapareço: não existo mais em parte alguma, eu sou, enfim!, sou em toda parte." (Sartre 3, p. 162; 4, p. 122-3)

Pois bem, dir-se-á, uma vez que ele nos apresenta seu estilo de pensamento como inseparável de seus ridículos e de suas quimeras, é porque então ele se descarta de sua filosofia ao mesmo tempo que de sua infância e de seu Eu empírico. Ele mesmo pensa isso, talvez. Mas, nesse ponto, é mais difícil segui-lo. Pois essas páginas seriam incompreensíveis, se não pressupusessem essa filosofia: essa infância premonitória, sua lucidez sempre à espreita, a própria relação que ele ousa estabelecer com seus primeiros anos, tudo isso seria um conto de fadas incrível se a filosofia de Sartre não fosse coerente e se seu rigor não fosse a caução da boa-fé do relato. Ao acusar-se, ele não pretende de modo algum justificar-se obliquamente: pusemo-nos de acordo sobre isso. Mas ele faz algo melhor: justifica briIhantemente seus conceitos. A infância catastrófica que, se lhe damos ouvidos, foi a sua, é evocada ainda e sempre em temos de liberdade. Liberdade desorientada, mas assim mesmo liberdade, sempre a ponto de retomar suas cartas - como o sonhador é mestre de seu sonho, mesmo que não possa fazer outra coisa senão suportá-lo.

A gente não se cura de si próprio, escreve ele. A gente se cura menos ainda de sua filosofia, quando se é um grande pensador. Esse livro é a luminosa (e talvez involuntária) demonstração disso - em que o autor, levando a honestidade intelectual até bem perto do masoquismo, reencontra a validade de seus conceitos no próprio momento em que quereria sem dúvida relativizá-los. Esse menino burguês pretensioso é também e sobretudo uma liberdade que, desde já, se recuperava à medida que afundava na mentira. Decididamente, "o pior nem sempre é garantido".

"Quando me falam de liberdade, dizia outrora Sartre, é como se me falassem de mim". E Merleau-Ponty, que cita esse dito, acrescenta esta frase que poderia servir de epígrafe a As Palavras: "Ele se confunde com essa transparência e essa agili idade que não é do mundo". Frase em que se pode notar aliás um pouco de ironia, já que Merleau-Ponty estava mais atento ao outro lado da liberdade: o espírito que sempre nega por isso mesmo afirma sempre, não é possível deixar a vida nem o mundo e não nos desengajamos de uma tarefa senão para engajar-nos em outra... Tal não é a consciência pura de que As Palavras são a história, afinal de contas, tranquiilizadora. Desde a mais tenra idade, ela nunca conseguiu obnubilar-se, apesar de todos os seus esforços. Sua loucura nunca pôde desabrochar, pois se negava à medida que era vivida. Sua seriedade nunca pôde ser total, pois nunca deixava de ser um subterfúgio irônico. E o livro é apenas a explicitação dessa negação em ato. O homem Sartre perde tudo nele, ou quereria perder tudo, a nossos olhos; sem que ele o quisesse, sua filosofia ganhou. Quanto mais o autor se fustiga mais lhe presta homenagem. Quanto mais se acusa, mais exalta - não o acusador: isso seria farisaísmo - mas o Nada que é e sempre foi. Está bem além do pudor e, todavia, escapa às armadilhas, da falsa hu- 
mildade ou do cinismo interessado. De suas confissões, não espera nada: por que faria dele uma apologia indireta? Apologia em favor de quem? 0 para-si não é nada, ele já mostrou isso; apenas um desabrochamento sem origem, se quisermos empregar uma imagem. Nunca pois um homem se ofereceu tão alegremente em holocausto a sua doutrina. Tal é, entre tantos outros, um dos benefícios da categoria do negativo, quando se sabe utilizála com habilidade.

\section{Bibliografia}

1. Rousseau, J-J. Les Confessions. Paris, Gallimard, 1964.

2. Sartre, J. P. L'Être et le Néant. Paris, Gallimard, 1943.

3. - Les Mots. Paris, Gallimard, 1964.

4. _. As Palavras. São Paulo, Difel, s/d.

5. _. Jean Genet, Comédien et Martyr. Paris, Gallimard, 1952. 